\title{
Questões para pensar campanhas de cerveja e seus processos de midiatização: regulação e regulamentação ${ }^{1}$
}

\author{
Eneus Trindade \\ Pedro Hellín \\ Christiane Haruê Egi
}

Resumo: Este trabalho se refere à discussão sobre os sentidos da regulação aplicados ao consumo e à comunicação, bem como ao entendimento desse conceito frente às definições de regulamentação e autorregulamentação, que constituem parte da base para a formação do quadro teórico do projeto integrado - Cerveja, Publicidade, Regulação e Consumo: o olhar da comunicação sobre as marcas de cervejas contemporâneas e suas implicações na vida social de adolescentes. Tal abordagem visa conhecer processos de midiatização e presença das marcas de cerveja na vida dos adolescentes que vivem em São Paulo, pelo olhar da pesquisa em comunicação. Este texto procura gerar outros pontos de vista sobre a regulação social dos sentidos das campanhas de cerveja com base na Análise Crítica do Discurso e sua perspectiva de mudança social.

Palavras-chave: regulação; midiatização; publicidade; cerveja; comunicação

\begin{abstract}
Matters to ponder upon regarding beer campaigns and their processes of mediatization: rules and regulations - This article discusses the meanings of regulations applied to consumption and communication, as well as the understanding about this concept in terms of the definitions of regulation and self-regulation, which underpin the theoretical framework of the project-Beer, Advertising, Regulation and Consumption: the viewpoint of communications concerning beer brands and their implications in the social lives of teenagers. This approach seeks to understand how mediatization and beer brands affect the lives of teenagers living in São Paulo, based on communication research. The authors aim to identify other points of view about the social regulation of the meanings of beer campaigns based on Critical Discourse Analysis and its perspective of social change.
\end{abstract}

Keywords: regulation; mediatization; advertising; beer; communication

1 Trabalho fruto de pesquisa financiada pelo CNPq. Texto referente a trabalho apresentado no DT2- Publicidade e Propaganda do XXXV Congresso Brasileiro de Ciências da Comunicação, Fortaleza: UNIFOR/Intercom. 2012. 


\section{Introdução}

Este trabalho busca apresentar os sentidos de regulação frente à trajetória histórica das teorizações sobre o marco regulatório brasileiro (MATTOS, 2006; PACHECO, 2006), confrontando-os com as noções de regulamentação e autorregulamentação, aplicadas à comunicação publicitária, apresentando as distinções e equívocos entre os termos frente aos processos regulatórios em seus aspectos mais amplos, pautando o nosso diálogo em autores como Giacomini Filho (1991), Trindade (2012), Bucci e Augusto Jr (2012).

Em seguida, busca-se apresentar os limites da regulação econômica e de consumo frente à regulação social dos sentidos, utilizando-se, para isso, a Análise Crítica do Discurso (ACD) inglesa, sobre campanhas de cerveja. Como pressuposto, partimos de abordagem que procura abertura de caminhos para entendimento do que deva ser regulação em comunicação e o pensar, quiçá, suas políticas e seu marco regulatório a partir do objeto de estudo (o sistema publicitário cervejeiro e suas interferências no consumo do público adolescente), no caso desta pesquisa. Mas, cabe destacar que, neste artigo, não trataremos da recepção/consumo de campanhas de cerveja por adolescentes.

A perspectiva da regulação (negociação de interesses de setores produtivos frente às expectativas da promoção do bem comum para sociedade civil) deve se opor a visão de regulamentação ${ }^{2}$ das práticas midiáticas comerciais, que estão sempre sujeitas à obsolescência em função dos fenômenos da midiatização sóciotécnica (BRAGA, 2006), que geram formas de publicização (CASAQUI, 2011), na dinâmica de renovação do sistema publicitário (ROCHA, 2006), que não abraça todas as possibilidades de pontos de contato (DI NALLO, 1999) entre mensagens das marcas para os consumidores.

\section{Marco regulatório brasileiro e suas perspectivas atuais}

A definição de regulação nasce na economia, considerando a gestão das possíveis "falhas do mercado" na relação produção/demanda e oferta para consumo efetivo e suas potencialidades de crescimento; regulação, portanto, envolve negociação de interesses de grupos de setores produtivos frente aos interesses dos consumidores e do bem comum de interesse público. Tal processo se faz valer de instrumentos reguladores como a regulamentação de normas éticas, a criação de regras para setores produtivos e as regulamentações com força de lei, que dariam os contornos dos direitos e deveres de um dado setor para com a sociedade.

Esse olhar econômico com distintas nuanças, sempre está presente na constituição de sentido da regulação. Ao examinarmos os eixos teóricos de constituição do Estado regulador brasileiro, identificamos em Mattos (2006, p. 149-151), três perspectivas histórico-teóricas: modelo jurídico-institucional, concebido no âmbito do pensamento

2 A regulamentação pode ser entendida como instrumento de regulação que visa à criação de normas de conduta ética e regras, que podem chegar a ter força de lei. 
autoritário clássico; modelo analítico, proposto por Fernando Henrique Cardoso; modelo analítico, formulado por Celso Furtado e sua aproximação com a análise de Cardoso.

O modelo jurídico-instituicional surge com maior força nos anos de 1930, sobretudo, na Era Vargas e está diretamente associado à política nacional centralizadora de desenvolvimento do Estado brasileiro por empresas estatais, que instituiu forte aparato governamental para além das dimensões fiscais e monetárias. O Brasil, diferentemente da Europa, fez uma passagem de um país agrário para um país agroindustrial, regulado de forma autoritária, por meio de uma política pública patrimonialista de industrialização sem a devida constituição de uma sociedade liberal, que permitisse o devido amadurecimento e a articulação de sua sociedade civil.

Esse modelo se cristalizou politicamente nas formas de disputas de poder que se restringiam aos grupos dominantes com acesso aos canais de circulação de poder político e controle da máquina estatal. A sociedade ficou à mercê desses conflitos de interesses de grupos específicos, cujas decisões se mantiveram com grande distância dos interesses públicos, demarcando uma ausência de participação da sociedade civil, uma vez que o estado democrático não foi o horizonte desse processo civilizatório (ibid., p.144).

O segundo modelo refere-se ao trabalho intelectual de Fernando Henrique Cardoso, no qual o pensamento crítico combateu a formação dos "anéis burocráticos", constituídos como consequência do aperfeiçoamento do modelo jurídico-institucional autoritário. Mattos (ibid.) ao resgatar Cardoso:

[..] o Estado regulador brasileiro, por não estar fundado na representação de interesses da sociedade civil, teria representado na sua formação uma acomodação apenas dos interesses da administração tradicional, clientelista, nos seus vários níveis de organização de poder. Tal argumento está em linha com a tônica da análise feita por Raymundo Faoro em Os donos do poder, ao afirmar que, diante da tecnocracia nascente no plano de um Estado centralizador com feições autoritárias, o patrimonialismo teria permanecido como característica da formação da burocracia estatal brasileira e os estamentos burocráticos teriam se institucionalizado. (lbid., p.144)

Essa compreensão sobre os "anéis burocráticos", na sua forma de regular o desenvolvimento do país, legitimava-se pelo apoio popular, porém, sem a representação ou com pouca representação da sociedade civil. Isso levou Fernando Henrique Cardoso, como presidente, de 1990 a 2002, constituir as agências reguladoras nacionais (marco regulatório). Elas, por sua vez, devem funcionar com autonomia e controle do papel regulador do Estado (PACHECO, 2006, p. 523). Dessa forma, deslocou-se do espectro dos três poderes, o papel regulador, na perspectiva de favorecer autonomia das agências frente aos setores regulados. Contudo, isso gerou incongruências de esferas que não aproximam devidamente a sociedade civil das discussões reguladoras, não oferecendo devida força a essas agências. 
Tais aspectos são mais compreensíveis ao resgatarmos o sentido de regulação em Celso Furtado, que buscava correções no processo regulatório a partir de uma política pública sistêmica de desenvolvimento econômico por regiões, equacionando problemas de desigualdade, que permitissem, posteriormente, paulatina abertura para participação efetiva da sociedade civil, principal interessada nas ações reguladoras de uma sociedade.

Todavia, o modelo que vigorou pós-Ditadura Militar foi o de Fernando Henrique Cardoso que, embora tivesse pontos em comum com Celso Furtado, fez a opção pelo descrédito ao Estado na condução do processo regulatório, deixando esse processo na mão das agências que não apresentam suas políticas de interação cristalizadas e bem pouco compreendidas nos âmbitos dos governos Lula e Dilma. Não se percebe a definição clara do papel das agências, mas arriscamos afirmar que elas aos poucos parecem ganhar força.

Portanto: como ativar a participação dos representantes da sociedade civil? Qual o papel das agências reguladoras e sua força na regulamentação/legislação dos setores produtivos, preservando os interesses sociais? Quais critérios subsidiariam decisões de investimento em pesquisa e desenvolvimento na compreensão dos setores, das potencialidades de inovação, a partir de fundos setoriais de gestão, que se prestam ao delineamento de novas políticas públicas? Ademais, nem todos os setores produtivos têm agências reguladoras e o papel regulador está em processo de consolidação social no país.

$\mathrm{Na}$ comunicação, em que a visão está pautada pela regulamentação (criação de normas éticas de conduta sem força de lei e leis pontuais), percebe-se que ações reguladoras poderiam se encontrar distribuídas entre a Anatel (Agência Nacional de Telecomunicações) e Anvisa (Agência Nacional de Vigilância Sanitária), cujos focos são as transmissões de comunicação e concessões de espaços midiáticos. Ambas estão voltadas às questões de saúde pública, percebendo a comunicação como algo a ser regulamentado (normatizado) e numa perspectiva, muitas vezes, reducionista das teorias dos efeitos, como diria Wolf (1999), pois a regulamentação interditaria aquilo que a comunicação estimula, no caso da publicidade, especificamente, que pode levar a respostas indesejáveis sobre o comportamento e condutas dos cidadãos em seus usos e consumos da vida cotidiana. ${ }^{3}$

Essa mirada sobre os meios e seus conteúdos afasta a possibilidade de discussão sobre a regulação de sentidos, substituindo-a pela noção de regulamentação (instrumento regulador normativo e de caráter legislativo quando adquire força de lei) de conteúdos nem sempre fiscalizáveis, frente aos processos de publicização que transcendem formatos publicitários tradicionais e formas regulamentadas de comunicar. Também negligencia o potencial do uso da publicidade como instrumento de difusão dos argumentos contra as condutas a serem combatidas no ambiente social.

Essa visão simplista da comunicação se pauta na equação falsa da publicidade como causadora e geradora de um dado efeito social, estímulo-resposta a ser combatido

3 Não se discute a Regulação na sua forma ampla, pelo seu caráter de negociação dos interesses setoriais e da promoção do bem comum público, bem como do entendimento de seus instrumentos como a regulamentação em leis, normas de conduta ética, regras para os setores de atividades econômicas. 
na esfera social. Quando de fato, os fatores que condicionam comportamentos de consumo midiatizados se dão na ordem de aspectos multifatoriais.

\section{Autorregulamentação publicitária e seus entraves à regulação}

A razão desse desvio de sentido, no que se refere à discussão de ações regulamentadoras da publicidade se explica ao recuperarmos o contexto e o sentido da criação do Conar (Conselho Nacional de Autorregulamentação) no Brasil, na década de 1980.

Nessa discussão, não se pode deixar de lado a importância, no setor publicitário, do Conar, oficializado em estatuto em 05/05/1980, São Paulo-SP, com seu Código e Anexos, que se associa ao surgimento do Código de Defesa do Consumidor (Lei $\mathrm{n}^{\circ} 8.078$, de 11 de setembro de 1990). O órgão representou grande avanço nos anos de 1980, entretanto, apresentava também signos de retrocesso. Sobre essa importância, assinala-se a contribuição de Giacomini Filho (1991) que, pioneiramente pensou, no cenário brasileiro, as relações entre consumidor, publicidade e consumo responsável.

O Conar é fruto de articulação do setor publicitário contra uma proposta governamental de censura à publicidade nos anos de 1970, pois como coloca o referido órgão em sua página institucional:

O Governo Federal pensava em sancionar uma lei criando uma espécie de censura prévia à propaganda. Se a lei fosse implantada, nenhum anúncio poderia ser veiculado sem que antes recebesse um carimbo "De Acordo" ou algo parecido. [...] As implicações burocráticas seriam inimagináveis ainda assim desprezíveis diante do retrocesso que tal controle representaria para um país que reconquistava a duras penas seu direito à liberdade de expressão. ${ }^{4}$

Aqui começa o engano. Na tentativa de evitar um processo de censura da publicidade, o setor se organiza para se autorregulamentar. Em termos filosóficos e epistemológicos, nenhuma instituição social pode se autorregular, a regulação se dá num processo de alteridade, frente ao outro. O instrumento da autorregulamentação implicaria, portanto, num desvio ontológico, ético, que institui uma problemática: como se autorregular e autorregulamentar-se? ${ }^{5}$

O meio publicitário faz ações comunicativas prevendo a sanção punitiva do Conar, a ação é feita para gerar polêmica e mídia espontânea sobre campanhas de anunciantes. O exemplo Devassa, estudado por Souza (2011), mostra as fragilidades do sistema de autorregulamentação. Além disso, o órgão atua em função dos interesses do setor

4 Conar: <http://www.conar.org.br/história>. Acessado em 23 de junho de 2012.

5 A regulação existe na negociação de interesses plurais, setores produtivos versus interesses sociais. Nesse sentido, como a autorregulamentação, como instrumento regulador, poderia trabalhar contra os interesses do próprio setor que representa? A autorregulamentação pode existir como uma peça a mais, no conjunto dos instrumentos reguladores, mas, por sua vez, ela tem que se submeter a órgãos e instrumentos de regulamentação ligados aos mecanismos de regulação de Estado para promover de fato o bem comum à sociedade civil. 
publicitário ao ser contra a interdição de publicidades, sobretudo, no caso das cervejas, alegando o prejuízo à liberdade de expressão.

A questão da cerveja envolve consumo de bebidas alcoólicas e questões de saúde pública e consumo ilegal por menores de idade. O argumento do cerceamento da liberdade de expressão é algo que parece torpe, frente às dimensões de saúde pública e do direito. É preciso que o setor publicitário relativize suas posições, estando mais aberto ao diálogo por meio das reivindicações sociais e pela consideração das pesquisas que mensuram e explicitam qual a participação das campanhas de cervejas na vida social de adultos e jovens para uma tomada de decisão mais restritiva à comunicação publicitária desse segmento.

Não é a relação comunicacional, estímulo-resposta, idealizada pelas áreas do direito e da saúde pública, nem é a liberdade de expressão clamada pelo setor publicitário, mas, é o entendimento desse processo de midiatização cultural na construção de lógicas de consumo que deve ser avaliada, bem como as possibilidades de regulação de sentidos gerada pela utilização da própria publicidade no combate às condutas que são problemas de interesse público. Parece que a publicidade prefere ficar na discussão argumentativa e superficial do que demonstrar o seu papel midiatizador em parâmetros científicos comunicacionais. ${ }^{6}$

Bucci e Augusto Jr. (2012) discutem a liberdade de expressão na publicidade, tratando que esta deve ser diferente da liberdade de imprensa, pois ao contrário desta última, a publicidade trabalha sobre interesses comerciais, econômicos e que quase sempre não são os interesses da sociedade. Aí reside a importância da regulação (como negociação), aqui manifestada. Por outro lado, em posição distinta, aqui defendida, talvez, por desconhecimento, os autores do artigo citado fazem um elogio ao "êxito do Conar", o que aqui merece uma relativização pelas razões enunciadas anteriormente.

O Conar conseguiu criar alguns limites básicos à publicidade, em função da incorporação da regulamentação de aspectos já legitimados no âmbito social, que se manifestam nas ações julgadas pelos seus 180 conselheiros (representantes da sociedade civil e da área publicitária), pautados no Código de Regulamentação Publicitária, seus anexos da $\mathrm{A}$ a $\cup$ e suas súmulas. Mas esse órgão está bem distante de ter um papel regulador efetivo, pois sua visão se restringe à questão frágil do regulamentar/proibir versus não regulamentar/permitir, ou tirar de circulação ou não tirar de circulação, pois sua atuação não tem valor de lei. A perspectiva do órgão é restrita e sem visão ampla de sentido social a ser construído para o processo civilizatório da sociedade, pois suas ações são pontuais e não promovem o efetivo desenvolvimento do setor publicitário com vista às mudanças sociais. É preciso sair do patamar da autorregulamentação e da regulamentação para entrar na regulação de fato.

6 Aqui nos referimos a dois lugares de contribuição das ciências da comunicação: o primeiro para o entendimento da regulação de sentidos na negociação dos posicionamentos dos discursos da saúde, da economia/mercado, dos direitos do consumidor e do senso comum, na mediação do sistema publicitário. E o segundo para pesquisa e desenvolvimento no setor comunicacional que favoreça o desenvolvimento da área em acordo com os interesses da sociedade civil, como estudos da comunicação de risco e de comunicação afirmativa, por exemplo. Ver (BATISTA, 2007). 
Talvez, como caminho para entender o problema exposto, traz-se a contribuição para identificação do que pode ser chamado de regulação social de sentidos pela publicidade, com vistas a uma proposta maior de criação de uma Agência de Comunicação e Cultura, em que a função seria regular toda comunicação, o que poderia ser uma alternativa para se trabalhar os sintomas da midiatização na vida social com pesquisas financiadas por fundos setoriais, trabalhando o objeto comunicacional, pelo monitoramento do espaço midiático, como no caso da pesquisa que dá origem a este trabalho.

\section{Regulação de sentidos em campanhas de cervejas}

Esta parte do estudo tem entre seus objetivos a função de realizar a ACD proposta por Fairclough (2001), das campanhas de cerveja entre 2008 e 2011, com vista à crítica ao processo de midiatização gerado por esse setor na vida social, para compreender as práticas discursivas sugeridas como práticas sociais estabelecidas nas propagandas de bebidas alcoólicas, com foco na cerveja, que se constitui como um importante elemento da vida alimentar presente na cultura brasileira.

Organismos da saúde e da regulação, como a Anvisa, discutem, atualmente, a possibilidade de regulamentar ou não a proibição de campanhas de cerveja nos meios. Mas qual o fundamento para isso? Em que medidas as práticas legais utilizadas nos últimos anos têm se mostrado eficientes para regular os discursos das campanhas de cerveja? Faz-se necessário a crítica aos discursos dessas campanhas para promover, por meio das práticas discursivas midiáticas, as práticas sociais responsáveis referentes ao consumo de álcool, sobretudo, as cervejas, inclusive no que se refere à influência das campanhas do setor junto ao público adolescente, objeto maior da pesquisa do qual este texto é parte.

Isto posto, cabe esclarecer que realizamos levantamento e classificação de anúncios impressos de revistas (Veja e Época) e comerciais de tevê entre 2008 e 2012, para verificação do tratamento discursivo dado à temática "bebidas alcóolicas e consumo por adolescentes". Contudo, para fins analíticos, daremos destaque neste artigo, em acordo com a discussão proposta, à análise de um comercial de tevê.

A partir desse quadro, destaca-se que as peças televisivas e gráficas foram classificadas nas seguintes categorias de argumentos/temas: qualidade do sabor/ingredientes/tradição; mulher/conquista; emotivo; diversão/amigos e anúncio de novo produto. Contudo, duas exceções podem ser apontadas, ambas da marca Brahma, Agência África: uma veiculada, em outubro de 2010, "AMAR" e a peça "Juiz - Consumo Responsável" de janeiro de 2011.

A primeira exceção pode ser classificada de início como tendo um argumento relacionado à diversão/amigos, mas o que ela apresenta de incomum é o fato dos protagonistas não obedecerem à regra "futebol/homens/cerveja". A quebra de estereótipo está no fato das mulheres serem as principais consumidoras do produto e estarem reunidas para beber e comemorar. Percebe-se a transferência de valores e modos do universo masculino para o universo de consumo feminino. 
A segunda, tratada mais profundamente neste artigo, possui argumentos diferenciados, que não se preocupam apenas com o consumo em si, mas com a qualidade do consumo. O comercial trata sobre o consumo responsável e a orientação que os pais devem dar a seus filhos sobre bebidas alcoólicas. Vê-se aí uma preocupação incomum do anunciante em orientar com responsabilidade a venda e o consumo de seu produto.

$\mathrm{O}$ comercial tomou como princípio básico elementos relacionados à cerveja, o seu consumo em bares e o futebol. Mesmo utilizando informações de advertência, que muitas vezes são consideradas "chatas, enfadonhas", ao utilizar-se de uma personalidade importante do meio futebolístico, conseguiu argumentar favoravelmente "menor e bebida alcoólica não jogam no mesmo time". A aproximação de um vocabulário relacionado ao futebol contribui para adicionar humor e identificação com o conteúdo.

A partir da constatação dessa diferenciação argumentativa, analisou-se inicialmente este caso excepcional entre todos os demais levantados. Aplicou-se a teoria segundo a ACD inglesa, baseada nos estudos de Fairclough. E é possível dizer que esse tipo de comercial pode trazer contribuições para as práticas sociais do consumidor de modo a interferir positivamente em seus rituais de consumo.

Quase a totalidade dos anúncios e comerciais conseguiram estar agrupados dentro de temáticas relacionadas à mulher, ao divertimento entre amigos, festas, anúncio de novo produto ou argumentos baseados na tradição da marca, no entanto, é necessário ressaltar que nem todas se apresentaram dentro dessa classificação. Existe a exceção, o comercial da Brahma, realizado pela Agência África em 2011, ao contrário das demais peças classificadas, a mensagem tem por objetivo principal a conscientização do uso/ consumo regulado de bebida alcoólica.

Isso é demonstrado ao apresentar Cafú, ex-jogador da seleção brasileira, dialogando sobre "menor e bebida alcoólica", a partir do argumento de que esses dois elementos não "jogam no mesmo time". Em outras palavras, esse comercial segue parâmetros condizentes com o que está explícito no site do Conar sobre a regulamentação da propaganda:

Princípio da proteção a crianças e adolescentes: não terá crianças e adolescentes como público-alvo. Diante deste princípio, os Anunciantes e suas Agências adotarão cuidados especiais na elaboração de suas estratégias mercadológicas e na estruturação de suas mensagens publicitárias. (CONAR, Anexo "A" Bebidas Alcoólicas).

Além disso, também entra em acordo com o que está no artigo 243 do Estatuto da Criança e do Adolescente, no qual se veta a venda de bebida alcoólica para menores de idade. Assim, percebe-se que o incomum nessa peça é a preocupação não com a venda do produto, mas sim com sua utilização de acordo com as leis sociais vigentes no país.

Diferentemente da maioria dos anúncios identificados, a publicidade não incentiva o consumo da bebida através de argumentos associativos como diversão, mulheres, festas, amigos e apelos emotivos. O consumo não é colocado em primeiro lugar, mas sim 
a qualidade de vida dos indivíduos que fazem uso do produto. Dessa forma, não ocorre a quebra de parâmetros sociais tradicionais, como é a relação entre pais e filhos, mas, sim reafirma essa hierarquia.

O poder da publicidade em relação ao consumo tem importância social. O discurso não tem por objetivo somente persuadir à compra, mas também causar mudanças na sociedade de modo a trazer ou não benefícios. Vê-se que o "Juiz" do comercial está ali para discursar sobre uma fronteira que não é bem percebida, nem bem tratada publicamente, que é o diálogo entre pais e filhos sobre bebidas alcoólicas, porém isso faz parte do conhecimento, da práxis dos indivíduos.

Mencionar a hierarquia social familiar coloca em ordem conflitos em situações mais concretas, que segundo Fairclough (2001, p. 128), vem para tentar "resolver os dilemas pela inovação". Nesse sentido, a peça contradiz os ideais vigentes em relação ao consumo. Muitas vezes, o anunciante ou a agência não se preocupam com seu público-alvo, pois tomam como premissa o lucro a qualquer custo. E contraditoriamente, o comercial resgata valores que talvez já não sejam tão enfatizados na mídia, como essa relação de hierarquia, ressaltando a responsabilidade dos pais sobre seus próprios filhos.

Interessa ressaltar que essa mensagem desafia o conceito de família mais comum difundido na mídia, mas confirma a estrutura social que está marcada no imaginário da sociedade como sendo a correta.

O que se pode ver na grande maioria das peças publicitárias é o desprendimento do consumidor para conseguir a bebida em situações inusitadas e até mesmo surreais, sustentadas principalmente pelo humor. Ou seja, elas não se baseiam na ordem social e buscam quebrar a realidade, o que acontece de modo contrário no comercial analisado.

Uma forma de analisar a prática social à qual pertence o discurso em termos de relações de poder, isto é, se essas relações de poder reproduzem, reestruturam ou desafiam as hegemonias existentes - como um modelo - uma forma de analisar a própria prática discursiva como um modo de luta hegemônica, que produz, reestrutura ou desafia as ordens de discurso existentes. (lbid., P. 126).

Uma questão importante é analisar o quanto a peça pode ser impactante e como ela pode atuar sobre a prática social do consumidor. Se isso pode ou não ser efetivo. Para tanto, podemos dizer que, baseado na teoria de Fairclough (ibid.) da ACD, podemos encontrar nessa peça três perspectivas analíticas que se baseiam nos níveis: ideacional, interacional e textual, como mostra Trindade (2011), na aplicação dessa teoria aos estudos da publicidade:

A prática social está para a dimensão ideacional (plano ideológico), em seus sentidos, suas pressuposições, metáforas, valores hegemônicos, orientações econômicas, culturais, políticas e étnicas. Já a prática discursiva revelaria a produção, circulação e consumo de discursos dentro dessa lógica hegemônica 
ou de resistência à hegemonia, considerando o contexto dos discursos, o jogo de forças, a coerência e as intertextualidades; isso mostra a dimensão interacional dos discursos em suas práticas. Por fim, o texto é o lugar onde os signos ganham concretude e, nele, observar-se-ia o vocabulário, as questões gramaticais, a coesão textual e a estrutura textual, como mecanismos linguísticos que a ACD considera formas de acesso à reflexão das questões sociais. (TRINDADE, 2011, p. 178).

Utilizando o critério de articulação de Fairclough (2001) como dispositivo, podese apontar que esses níveis se desdobram em elementos representacionais/ideacionais, relacionados à ideologia que desejam dar lugar; elementos identificacionais/interacionais, que dizem respeito à identidade cultural e elementos acionais/textuais, que se traduzem em ações textuais concretas, nas quais o estilo textual revela as práticas de uma sociedade.

O nível acional possui elementos que se dividem em: vocabulário, gramática, coesão e estrutura textual. A seguir, para melhor analisar o texto falado na propaganda, foram transcritas as falas dos atores:

Cafú: Todo "Brahmeiro" é apaixonado por futebol.

Juiz: Por isso, estamos aqui pra falar de um assunto de "responsa": Menor e Bebida.

Cafú: Se você é pai e não fala isso com seus filhos...

Juiz: (aponta o cartão vermelho) É falta grave.

Cafú: E oferecer bebida para menor...

Juiz: Também "leva vermelho". (aponta o cartão)

Cafú: Menor e Bebida não podem jogar no mesmo time.

Juiz: (pega um pão); Cafú: Oche, o que é isso? Metendo a mão?

Narrador: Brahma, menor e bebida é bola fora. Produto destinado a adultos.

Como é possível analisar, o vocabulário utilizado é compatível com o tema futebol. Gírias e expressões enfatizam a informalidade e a proximidade do jogador com o espectador que está sendo "orientado", como se pode perceber pelo uso dos termos "brahmeiro", "leva vermelho" e "assunto de responsa".

Assim, como em uma dissertação, o tópico principal da publicidade apresenta uma estrutura clara, na qual se apresenta o assunto e a tese (menor e bebida), desenvolve-se um raciocínio: "Pais e filhos devem conversar sobre bebidas alcoólicas", cujas consequências são: "se não falam... devem ser punidos com cartão vermelho". Em segunda instância, alerta-se para outro tópico vinculado ao primeiro, o que demonstra coerência, que é a prática de não oferecer bebida a menores de idade, fazendo o desfecho com uma piada.

Essas expressões específicas trazem consigo elementos da prática discursiva, o que revela seu nível interacional e identificacional, pelo contato com pontos marcantes da cultura brasileira, fatos considerados como senso comum e corriqueiros junto ao público brasileiro que relaciona futebol e consumo de cerveja, só que agora manifestando o interdito ao consumo por menores de idade. 
Assim, ocorre a interdiscursividade entre dois elementos que aparentemente não teriam relação alguma, se não fossem associados por meio da cultura e da tradição. Fatores que tiveram que ser construídos e associados por meio de um grande número de inserções na mídia, mas que também refletem a realidade dos consumidores.

A associação entre as regras do futebol e a educação de jovens em relação à bebida alcoólica está intrinsecamente ligada, nessa publicidade, ao que se chama de nível ideológico ou ideacional. Por meio de um argumento de autoridade por parte do jogador Cafú, o consumidor pode ser convencido de que "menor e bebida" não são elementos que podem estar associados, o que leva à comparação de "não estarem no mesmo time".

Percebe-se que há predominância do elemento representacional do politicamente correto, na tentativa de incutir no consumidor uma consciência maior sobre o tema, existe neste caso a utilização de padrões ideológicos socialmente aceitos como os ideais pela população. Isso pode ser percebido ao se colocar como critério de argumento à idealização de um pai que é responsável, preocupa-se e controla aquilo que seu filho está consumindo. Do mesmo modo, o conceito de filho ideal também está aqui aplicado: um indivíduo que provavelmente ouvirá o adulto e não transgredirá as regras colocadas.

Não são apenas essas as representações apresentadas. Brahma também se coloca como sendo uma marca ideal, aquela que não está apenas preocupada em fazer vender seu produto, mas que entende a realidade e as dificuldades do consumidor, dando uma atenção especial à qualidade de vida deste.

A mensagem politicamente correta, que busca ser a principal no comercial, vem também com informações secundárias imprescindíveis para o perfeito entendimento. A partir da premissa: "Todo Brahmeiro é apaixonado por futebol" é possível chegar a outros elementos conclusivos. Estes podem estar subentendidos com o seguinte silogismo: "Todo brasileiro é apaixonado por futebol", "Todo brahmeiro é apaixonado por futebol", portanto "Todo brasileiro é brahmeiro". A marca ao aproximar elementos culturais, como o futebol, dos argumentos já explicitados, revela sua dimensão argumentativa que busca aproximar o consumidor da marca, de modo a poder interferir positivamente em seus hábitos.

Dessa forma, chega-se ao ethos que, segundo Trindade (2011, p. 182), configura-se "no fato de que o enunciador/emissor pressupõe, em seu discurso, uma imagem formulada de si e de seu enunciatário/receptor para criar um pathos, um efeito de sentido discursivo possível sobre seus enunciatários, projetado no discurso". No caso desse comercial, o ethos baseia-se principalmente na credibilidade da marca, ao pedir que pais e filhos dialoguem, a fim de chegarem ao consumo responsável de bebida alcoólica, levando em consideração que menor e bebida não devem andar juntos.

Aqui persiste uma idealização social da família, na qual pais e filhos, unidos, podem chegar a um consenso aparentemente sem grandes discussões ou problemas. Pais devem ser responsáveis e filhos devem ser obedientes, o que na realidade, muitas vezes, não ocorre na atualidade. 
O pathos apresentado relaciona-se ao "meu ídolo fala, eu sigo". Ao utilizar o jogador Cafú para argumentar, inúmeras conclusões indiretas podem ser tiradas, muitas vezes não totalmente lógicas, mas sim relacionadas ao fator ídolo: Cafú, por ser pai, pode dar bons conselhos; ele é um jogador de sucesso, então sabe o que é certo e errado; quero ser como Cafú.

Utilizar uma celebridade pode ser um meio efetivo de impressionar ou até mesmo validar a mensagem que está sendo proposta. $\mathrm{O}$ anúncio mostrou-se como sendo de grande importância ao revelar uma exceção no meio publicitário das cervejas. Isso pode ser considerado como uma ação positiva, pois mostra a preocupação do anunciante não apenas em vender seu produto, mas por considerar valores sociais e sustentáveis para o comércio, o que verifica uma possível vertente a que a publicidade pode se vincular, no âmbito de sociedades reguladas, para a construção dos vínculos identitários entre marcas e consumidores.

\section{Considerações finais}

Entendemos que a regulação de sentidos da comunicação passa por uma política pública sobre o uso educacional das mídias, para gerar conteúdos que visam ao estímulo e à constituição, bem como à preservação da participação cidadã no mundo cultural midiatizado. A proposta do comercial analisado é um bom exemplo dessa performance criativa. Regulação não deve se restringir à regulamentação. E, necessariamente, a regulamentação da comunicação com interdições não significa a regulamentação do consumo de produtos. ${ }^{7}$ Existem hiatos nesses processos. Portanto, a questão é complexa e envolve as noções de: políticas reguladoras e marco regulatório; regulação de setores; regulação da economia/mercados; regulação de consumo e regulação de sentidos socioculturais, isto é, um amplo cenário de negociações de sentidos e interesses, como aqui tentamos delinear.

A regulação da comunicação é a regulação de um setor de atuação ampla, na perspectiva dos sentidos socioculturais de um dado contexto, diante das suas pretensas ações de políticas educacionais para a constituição de seus cidadãos. Hoje, as ações reguladoras da comunicação se dão de forma intermediada por outras agências, como a Anatel e a Anvisa, mas será que não seria o caso de pensarmos uma Agência de Regulação da Comunicação e Cultura?

Regular significa chegar a um patamar civilizatório, para dizer dentro de uma democracia participativa, qual tipo ou modelo de sociedade se quer, inclusive proibindo ou restringindo determinados tipos de ações comunicacionais publicitárias, pois não

7 Normalmente se entende regulamentação, a criação de leis, protocolos e normas como regulação. Regulação é um processo maior de negociação processual que engloba instrumentos regulamentadores com força de lei, normas éticas de condutas, regras de setores, como são os mecanismos autorregulamentadores dos setores, a exemplo do Conar, que devem trabalhar na perspectiva de subsidiar o trabalho de regulação estatal. 
defendemos a liberdade desregulada da publicidade, como apontam Bucci e Augusto Jr (2012), ao explicitarem que a publicidade trata de aspectos de risco pelo consumo, que precisam ser comunicados. Trata-se de questões de saúde pública e não de censura ou de cerceamento da liberdade de expressão. Longe de se chegar a uma conclusão, entende-se que este artigo abre um novo olhar para a comunicação, buscando outro entendimento dos processos publicitários na tessitura social.

Eneus Trindade é professor livre-docente da Escola de Comunicações e Artes da Universidade de São Paulo. É pós-doutor em Antropologia Visual pela Universidade Aberta de Portugal e líder do Grupo de Estudos Semióticos em Comunicação, Cultura e Consumo- GESC3 (CNPq).

eneustrindade@usp.br

Pedro Hellín é professor titular em Comunicação Pela Universidad de Murcia (Espanha). É doutor pela Universidad de Sevilla e professor do curso de Publicidade e membro do Grupo de Estudos Semióticos em Comunicação Cultura e Consumo GESC3 (CNPq).

Christiane Haruê Egi é bolsista de iniciação científica e estudante do Curso de Publicidade e Propaganda da ECA/ USP.

\section{Referências}

AGÊNCIA ÁFRICA. Brahma - Juiz Consumo Responsável, maio, 2009. Disponível em: <http://www. youtube.com/watch?v=MXANqzEAtZI>. Acessado em 30 jan 2012.

BRAHMA. "Amar", 2010. Disponível em: <http://www.youtube.com/watch?v=JFN3JaOPws\&feature=related $>$. Acessado em 23 jan. 2011.

BATISTA, Leandro Leonardo. "Comunicação de Risco". In: PEREZ, Clotilde; BARBOSA, Ivan Santos (orgs.). Hiperpublicidade. São Paulo: Cengage Learning, p. 429-447, 2007.

BRAGA, José Luiz. Sobre "midiatização" como processo interacional de referência. In: ENCONTRO ANUAL DA COMPÓS, 15. Anais... Bauru: Unesp/Compós, jun., p. 1-15, 2006.

BRASIL. Código de Defesa do Consumidor: lei n 8.078, de 11-/1990. Brasília, 1990. Disponível em: $<$ http://www.procon.sp.gov.br/pdf/2010-07-23-codigo\%20defesa\%20consumidor.pdf>. Acessado em 23 jun. 2012.

BRASIL. Presidência da República. Estatuto da criança e do adolescente: lei nº 8.069, Brasília. 
Disponível em: <http://www.planalto.gov.br/ccivil_03/Leis/L8069.htm>. Acessado em 20 abr. 2012. BUCCI, Eugenio; AUGUSTO JUNIOR, Silvio Nunes. A Liberdade de imprensa e a liberdade na publicidade. Revista Comunicação, Mídia e Consumo, São Paulo, v. 9, n. 24, 2012.

CASAQUI, Vander. Por uma teoria da publicização: transformações no processo publicitário. In: CONGRESSO BRASILEIRO DE CIÊNCIAS DA COMUNICAÇÃO/ INTERCOM, 35. Anais... Recife, Unicap/ Intercom, pp. 1-15, 2011.

DI NALLO, Egeria. Meeting Points - soluções de marketing para uma sociedade complexa. São Paulo: Cobra, 1999.

FAIRCLOUGH, Norman. Discurso e Mudança social. Brasília: UNB, 2001.

GIACOMINI FILHO, Gino. Consumidor versus Propaganda. São Paulo: Summus, 1991.

MATTOS, Paulo Todescan Lessa. A formação do estado regulador. Revista Novos Estudos CEBRAP, São Paulo, n. 76, nov, 2006. Disponível em: <http://www.scielo.br/scielo.php?script=sci_ arttext\&pid=S0101-33002006000300007\&lng=pt\&nrm=iso\&tlng=pt>. Acessado em 23 jun 2012.

PACHECO, Regina Silvia. Regulação no Brasil: desenho das agências e formas de controle. Revista de Administração Pública. Rio de Janeiro, FGV/Ebap, v. 40, n. 4, jul-ago/2006. Disponível em: <http:// www.scielo.br/pdf/rap/v40n4/31594.pdf>. Acessado em 23 jun 2012.

ROCHA, Everaldo. Representações do consumo: estudos sobre a narrativa publicitária. Rio de Janeiro: Ed. Mauad, 2006.

SOUZA, Sandra Maria Ribeiro de. A propósito de consumo, censura, cerveja e celebridade: a construção de sentido da marca Devassa. Revista Matrizes. São Paulo, v. 5, n. 1 jul-dez/ 2011. Disponível em: <http://www.matrizes.usp.br/index.php/matrizes/article/view/41/65>. Acessado em 23 jun 2012.

TRINDADE, Eneus. Perspectivas dos usos e consumos da imagem do negro na publicidade contemporânea brasileira In: BATISTA, Leandro Leonardo; LEITE, Francisco (orgs.). O negro nos espaços publicitários brasileiros; perspectivas contemporâneas em diálogo. São Paulo: Escola de Comunicações e Artes/USP, 2011, p. 173-185.

. A regulação e a comunicação no caso da publicidade de cervejas junto ao público adolescente: problemáticas. ENCONTRO NACIONAL DE PESQUISADORES EM PUBLICIDADE E PROPAGANDA, 3. Anais... São Paulo, Schoba e ABP2/ECA/USP, 2012, p. 84-100. Disponível em: <http://www.eca. usp.br/propesq/downloads/ebook_III_Propesq_pp.pdf>. Acessado em 30 jan 2013.

WOLF, Mauro. Teorias da Comunicação. Mass media: contexto e paradigmas. Lisboa: Presença, 1999. 